\title{
Acid-breakable Resin-based Resist for Nanofabrication
}

\section{Electron-beam Lithography}

\author{
Toshio Sakamizu, Tadashi Arai, and Hiroshi Shiraishi \\ Central Research Laboratory, Hitachi, Ltd., Kokubunji, Tokyo 185-8601, Japan
}

\begin{abstract}
A new chemical amplification positive resist system designed for nanofabrication electron-beam lithography is described. The positive resist system consists of an acidgenerator and an acid-breakable $(\mathrm{AB})$ resin that can be converted to polyphenol fragments by an acid-catalyzed reaction. The $\mathrm{AB}$ resin is synthesized through a co-condensation reaction between polyphenol and aromatic multi-functional vinylether compounds (bisvinylether and trisvinylether compounds). Molecular weight (MW) of the $\mathrm{AB}$ resin increases with an increase in the vinylether feed ratio. A condensation reaction with a polyphenol/vinylether feed ratio of 100/50 results in a high $\mathrm{MW}(\mathrm{Mw}>5000) \mathrm{AB}$ resin which is insoluble in an alkali developer (tetramethylammonium hydroxide: $2.38 \mathrm{wt} \%$ ). The acid-catalyzed fragmentation of the $\mathbf{A B}$ resin in the resist film was confirmed through gel permeation chromatography. The resist with the $\mathrm{AB}$ resin showed the high resolution of 80 -nm line-and-space patterns with high sensitivity $\left(5.0 \mu \mathrm{C} / \mathrm{cm}^{2}\right.$ at $\left.30 \mathrm{kV}\right)$.
\end{abstract}

Keywords: electron-beam, positive resist, acid-breakable resin, vinylether compound, acid-catalyzed fragmentation

\section{Introduction}

For the fabrication of nanoelectronic devices with sub-100-nm dimensions, electron-beam (EB) lithography is most useful technique. We have investigated a novolak resin-based chemical amplification (CA) positive resist, consisting of a novolak resin, an acetal-protected dissolution inhibitor, and an acid generator [1,2]. Although the resist enabled fabrication of $100-\mathrm{nm}$ contact hole patterns with high sensitivity $\left(6.0 \mu \mathrm{C} / \mathrm{cm}^{2}\right.$ at 50 $\mathrm{kV}$ ), the resolution was still insufficient for sub100-nm fabrication.

In a previous paper [3], we investigated nanometer-scale imaging characteristics of a novolak resin-based $\mathrm{CA}$ resist and the molecular weight (MW) distribution effects of the resin matrix. As described in the paper, the wide MW distribution, which results in high contrast of dissolution rates between exposed and unexposed regions of the resist, caused nanometer-scale line edge roughness in the fine pattern. However, the degree of edge roughness was greatly reduced in the fractionated novolak resin-based resist which showed lower resolution than the conventional novolak resin-based one. This paper reports on a new resin matrix of a CA positive resist for alkali development. This resin has high dissolution contrast that can be independent of the MW distribution.

CA resists for aqueous alkali development have achieved great success in recent sub-0.5- $\mu \mathrm{m}$ lithography. However, PMMA has been widely used as a high-resolution positive EB resist for nanofabrication. This is because a reduction in MW through the radiation-induced main-chain scission enables a large dissolution contrast in an organic developer. In the early stages of developing CA resists, acid-degradable polymers have been studied $[4,5]$. These polymers were used as a self-development imaging material and/or dissolution inhibitor in a novolak resin-based CA positive resist. Recently, Schacht et al. reported the use of acid-labile cross-linking units in their CA positive resist [6]. These cross-linking units lead to 
an increase in MW and improved dissolution inhibition, thus enhancing the thermal flow stability and resolution of the resist.

In this article, we describe acid-breakable (AB) resins synthesized by a co-condensation reaction between polyphenol and aromatic multi-functional vinylether compounds. Since polyphenol compounds are very soluble in aqueous alkali developer, such resins can act as an alkalidevelopable matrix resin in CA positive resists. Preparation and characteristics of the $A B$ resins are investigated. We also discuss the exposure characteristics of the $\mathrm{AB}$ resin-based resist. In addition, we report on the preliminary lithographic performance of the resist.

\section{Experimental}

2.1 Preparation of multi-functional vinylether compounds

The phenols used as starting materials of the aromatic bis- and trisvinylether compounds were 4,4'-dihydroxydiphenylmethane, 4,4',4"-trihydroxytriphenylmethane, and phloroglucinol purchased from Tokyo Kasei Kogyo Co. The vinylether compounds shown in Figure 1 were synthesized by the reaction of 2-chloroethylvinyl ether with a phenol in DMSO as described in previous articles $[7,8]$.

\subsection{Preparation of $A B$ resins}

$A$ series of $A B$ resins were synthesized in a similar manner as shown in Figure 2. We tested several vinylether compounds feed ratios (wt. ratios) for the preparation of the resins. The polyphenol/vinylether wt. ratios were $100 / 10$, $100 / 30$, and $100 / 50$. A typical example (wt. ratio of 100/50) is as follows. The polyphenol (2 $\mathrm{g})$ and EVE-1 (1 g) were dissolved in ethyl acetate solution $(100 \mathrm{ml})$ and pyridinium $\mathrm{p}$ toluenesulfonate (PTS) $(0.01 \mathrm{~g})$ was added to this solution as an acid catalyst. After the solution was stirred at room temperature for one day, the solution was washed with $3 \% \mathrm{NaOH}$ twice, and distilled water once. The solution was then dried over anhydrous sodium sulfate and concentrated under reduced pressure. The resin was precipitated in $\mathbf{n}$-hexane and purified.

\subsection{Materials}

The polyphenol investigated as a polyphenol unit in the $A B$ resin syntheses was supplied by Honshu Chemical Co. (Figure 1). The acid generators used in this study were $\mathrm{N}$ - ethanesulfonyloxy-1,8-naphthalimide (NAIOET), $\mathrm{N}$-nonafluoro-1-butanesulfonyloxy-1,8-

naphthalimide (NAIONO) [9], and tri(ethanesulfonyloxy)benzene (EtSB) [10]. An alkyl-substituted onium iodide was used as the additive for acid-diffusion control [11]. The commercially available aqueous-alkali developer NMD-3 (tetramethylammonium hydroxide: 2.38 wt\%, Tokyo Ohka Co.) was used as the developer. 2-heptanone (MAK) was used as a resist solvent.<smiles>Oc1ccc(C(c2ccc(O)cc2)c2ccc(O)cc2)cc1</smiles><smiles>[2H]OC1=CC(O)C(O)CC1O</smiles>

EVE-1

EVE-2<smiles>Oc1ccc(Cc2ccc(O)cc2)cc1</smiles>

R: $-\mathrm{CH}_{2} \mathrm{CH}_{2}-\mathrm{O}-\mathrm{CH}=\mathrm{CH}_{2}$

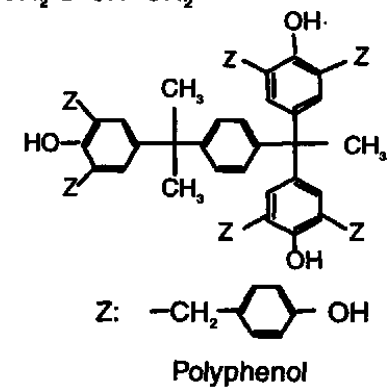

Figure 1 Chemical structures of vinylether compounds and polyphenol

\subsection{Characterization}

The chemical structures of the synthesized compounds were identified from IR spectra (Perkin-Elmer FT-IR 1720X) and NMR spectra (Varian Mercury $200 \mathrm{MHz}$ ). Gel-permeation chromatography (GPC) was performed using a Hitachi L-6000 liquid chromatography system equipped with Gelpak A-150, A-140 and A-120 GPC columns (Hitachi Chemical Co.) The GPC solvent was tetrahydrofuran. Thermogravimetric analysis (TGA) was done on a Shimadzu TG-40M and differential scanning calorimetry (DSC) was applied using a Perkin-Elmer DSC-7 at a heating rate of $10^{\circ} \mathrm{C} / \mathrm{min}$ for TGA and $20^{\circ} \mathrm{C} / \mathrm{min}$ for DSC in nitrogen. Electron-beam exposure characteristics were measured by a scanning electron microscopy at $30 \mathrm{kV}$ using a modified Hitachi S-570. Electronbeam lithography evaluations were conducted with a raster scan Gaussian beam EB writer at $30 \mathrm{kV}$. Deep-UV exposure at $250 \mathrm{~nm}$ was made with a $\mathrm{Xe}-\mathrm{Hg}$ lamp through an interference filter. The 
light intensity was determined with a calorimetric flux detector thermopile (JASCO INC.). The sample films were spin-coated onto silicon wafers and baked on a hot plate under various conditions. The film thickness was determined by using a profilometer, Alpha-step 200 (Tencor Instrument Co.). Fabricated patterns were observed by a scanning electron microscopy using a Hitachi S4200 .

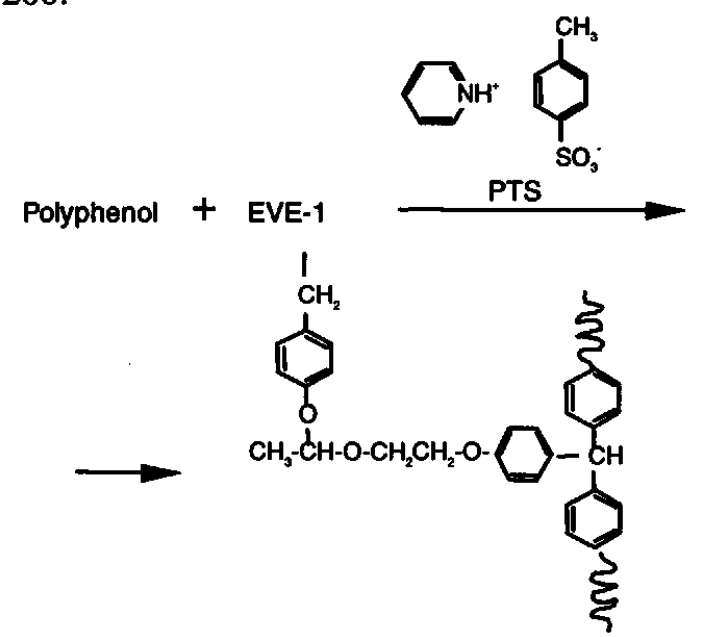

Figure 2 Acid-catalyzed condensation of polyphenol with EVE-1

\section{Results and Discussion}

\subsection{Physical properties of $\mathrm{AB}$ resins}

The effects of the structure and content of the vinylether on the physical properties of the $A B$ resin is summarized in Table 1 . As expected, the $\mathrm{MW}$ of $\mathrm{AB}$ resins increased with an increasing vinylether content. In the case of trisvinylethers (EVE-1 and EVE-2), at $30 \mathrm{wt} \%$ the MW was increased by a factor of about 5 compared with that of the polyphenol (Mw: 1060). By contrast, the bisvinylether (EVE-3) needed $50 \mathrm{wt} \%$ to obtain a high $M W$ resin $(M w>5000)$.

To estimate the flow stability of the resist patterns, we also measured $\mathrm{Tg}$ of several resins obtained with a vinylether content of 30 or $50 \%$, as shown in Table 1. AB-1c (50 wt\%) showed the highest $\mathrm{Tg}\left(103^{\circ} \mathrm{C}\right)$, and this was close to that of most conventional novolak resins used in positive photoresists. We ascribe the difference in $\mathrm{Tg}$ among these resins (with the same wt. ratio) to the difference in the melting points of these vinylethers. In addition, although it is well-known that the $\mathrm{Tg}$ of acetal-protected PHS decreases with an increasing acetal-protection degree [12], there was no evidence of a decrease in the resin's $\mathrm{Tg}$ when the vinylether content was increased (AB-2b and $\mathrm{AB}-2 \mathrm{c}$ ).
Table 1 Physical properties of AB resins

\begin{tabular}{|cccccc|}
\hline Resin & Vinylether & $\begin{array}{c}\text { PPNE } \\
\text { feed ratio }\end{array}$ & Mw & Mn & $\mathrm{Tg}\left({ }^{\circ} \mathrm{C}\right)$ \\
\hline AB-1a & EVE-1 & $100 / 10$ & 2150 & 1580 & - \\
AB-1b & EVE-1 & $100 / 30$ & 5700 & 2200 & \\
AB-1C & EVE-1 & $100 / 50$ & 8200 & 2200 & 103 \\
AB-2a & EVE-2 & $100 / 10$ & 1570 & 1410 & A8 \\
AB-2b & EVE-2 & $100 / 30$ & 7700 & 2500 & 78 \\
AB-2C & EVE-2 & $100 / 50$ & 8600 & 2100 & 80 \\
AB-3a & EVE-3 & $100 / 10$ & 1500 & 1100 & $=$ \\
AB-3b & EVE-3 & $100 / 30$ & 1800 & 1300 & \\
AB-3C & EVE-3 & $100 / 50$ & 8650 & 2400 & 86 \\
\hline
\end{tabular}

"Polyphenol/vinylether feed ratio

The TGA trace of $\mathrm{AB}-1 \mathrm{c}$, as an example, is shown in Figure 3. Up to $250^{\circ} \mathrm{C}$ there was little significant change in TGA, then at about $360^{\circ} \mathrm{C}$ thermal decomposition occurred. This behavior is similar to that of the novolak resin. Therefore, this decomposition temperature clearly demonstrates the high thermal stability that is obtained through the condensation between multi-functional vinylether and the polyphenol unit.

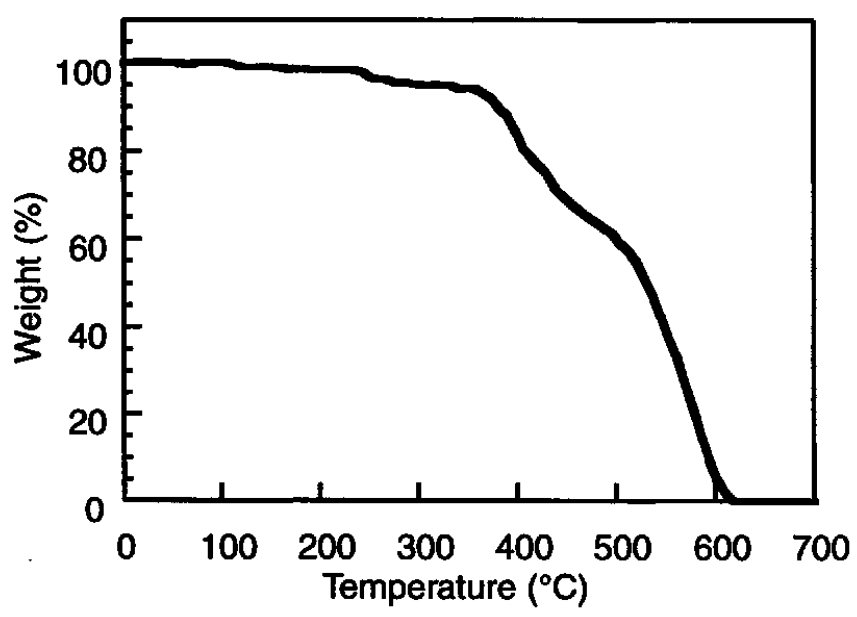

Figure 3 TGA curve of AB-1c

As $\mathrm{AB}$ resin is used as an insoluble matrix resin in the resist system, we evaluated the dissolution inhibition ability of the resins. The dissolution rates of the resins were measured as a function of the vinylether content, as shown in Figure 4. For the three vinylethers, a $50 \mathrm{wt} \%$ was enough to ensure negligible dissolution for alkali development. From this result, we expected the dissolution contrast between unexposed and exposed areas to be about four orders of magnitude, because the polyphenol unit should be regenerated in the exposed areas. 


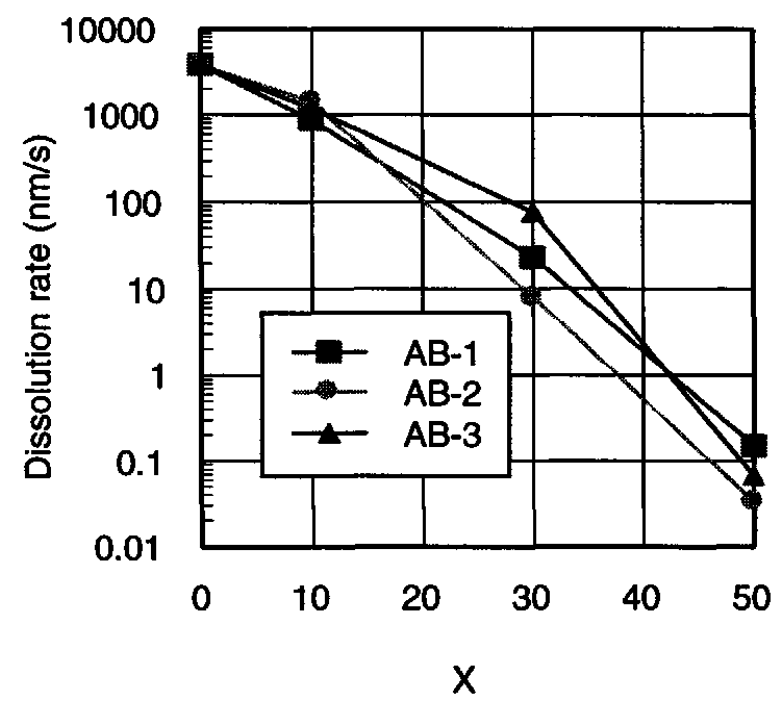

Figure 4 Change in the dissolution rate with an increase in the vinylether content. polyphenol/vinylether $=100 / \mathrm{X}$ (wt. ratio)

\subsection{Acid-catalyzed fragmentation of $\mathrm{AB}$ resin}

To investigate whether a large decrease in the MW occurs, the MW distributions of a model resist film with $\mathrm{AB}-1 \mathrm{c}$ were measured after prebaking (PB) $\left(90^{\circ} \mathrm{C}, 120 \mathrm{~s}\right)$, after deep-UV exposure $\left(10 \mathrm{~mJ} / \mathrm{cm}^{2}\right)$, and after post exposure baking (PEB) $\left(100^{\circ} \mathrm{C}, 120 \mathrm{~s}\right)$. The mode composition was $\mathrm{AB}-1 \mathrm{c} / \mathrm{NAIOET}=100 / 5$ (wt ratio). The results are shown in Figure 5. After PB there was no peak in lower MW region $(\mathrm{Mw}<1000)$, indicating that this resin was free from unreactive vinylether. Also, there was no difference in MW distribution before and after PB (not shown in this figure). After exposure there was little or no change in the MW distribution. This means the acidolysis of acetal moieties in the presence of a photogenerated acid does not occur at room temperature. By contrast, after PEB most of the higher MW components had disappeared, and both the polyphenol and the cleavage product $(\mathrm{Mw}$ : $\sim 500$ ) appeared. These results indicate this type of resin is susceptible to acid-catalyzed fragmentation.

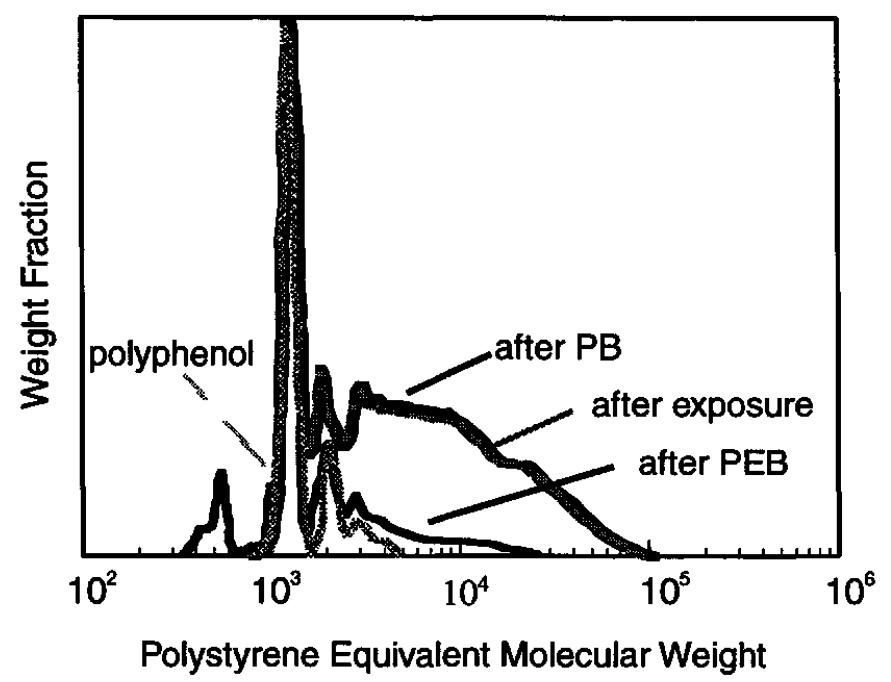

Figure 5 Molecular weight distributions of polyphenol and $A B-1 \mathrm{c} / \mathrm{NAIOET}=100 / 5$ mixture film after $\mathrm{PB}$, after exposure, and after PEB.

A reaction mechanism for the acid-catalyzed hydrolysis of a thermally cross-linked resist using a vinylether compound as a cross-linker has already been described [13]. To explain the mechanism of acid-catalyzed fragmentation of an $A B$ resin, we measured the ${ }^{1} \mathrm{H}-\mathrm{NMR}$ spectra of $\mathrm{AB}-1 \mathrm{c}$ before and after adding methanesulfonic acid in $\left(\mathrm{CD}_{3}\right)_{2} \mathrm{CO}$ solvent. Figure 6 shows the ${ }^{1} \mathrm{H}$ NMR spectra and the assignments of $A B-1 c$ before and after the acid was added. The methyl proton (a) of acetal groups appeared at about $1.3 \mathrm{ppm}$ in the spectrum of the neat AB-1c. The proton (a) disappeared when the acid was added, and this was accompanied by the appearance of new peaks ((f) and $(\mathrm{g})$ ) due to acetaldehyde. However, other proton peaks remained unchanged after the acid was added.

An acid-catalyzed fragmentation mechanism of AB-1 based on our ${ }^{1} \mathrm{H}-\mathrm{NMR}$ spectroscopic study and GPC analysis is summarized in Figure 7. Protonated phenolic oxygen liberates a phenol and an oxocarbenium ion during PEB. This carbenium ion can react with water from the atmosphere to give the hydroxy intermediate and regenerate a proton. Finally the cleavage products, that is, alcohol and acetaldehyde are produced by protonation at ether oxygen. These results suggest that the main fragmentation products are the initial polyphenol unit, a phenoxyethyl alcohol derivative, and acetaldehyde. 


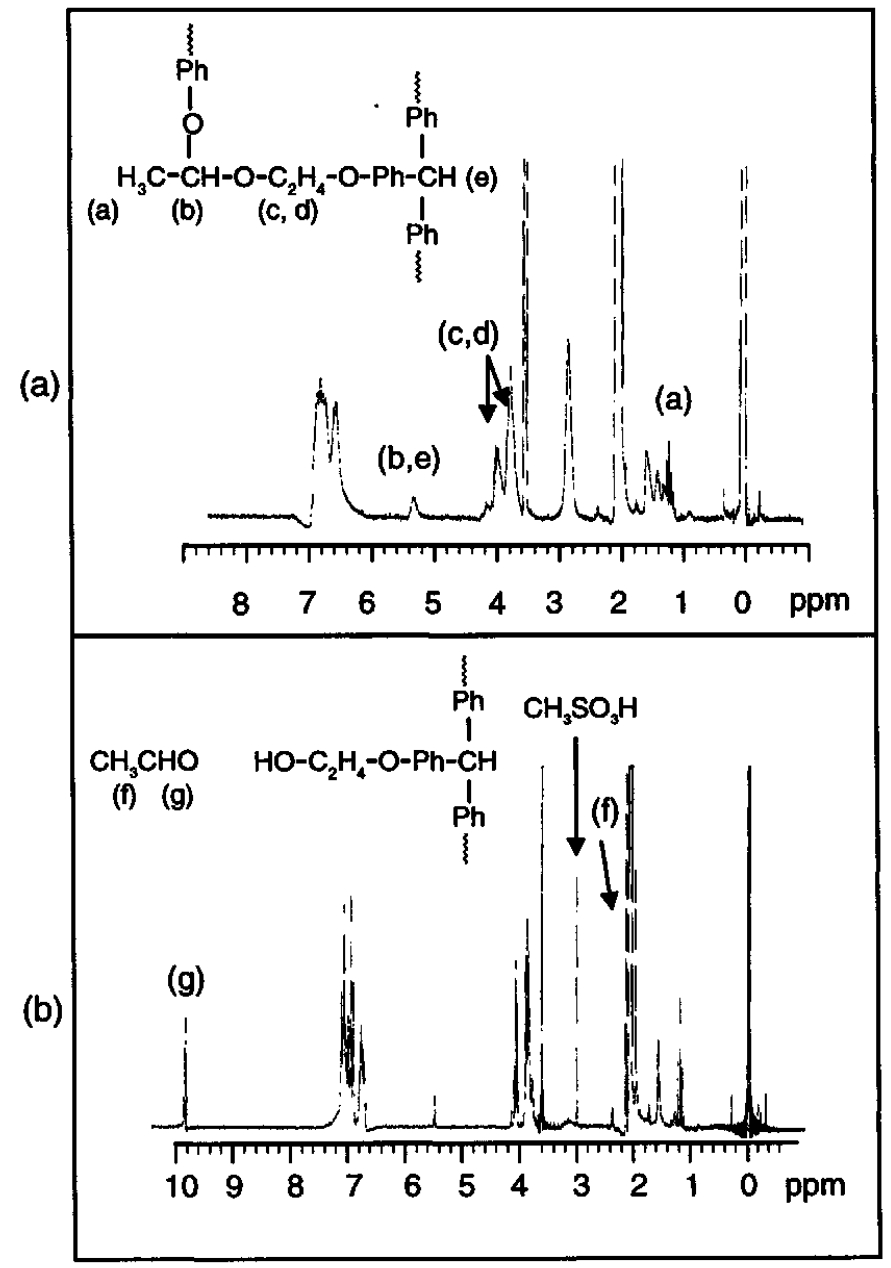

Figure $6{ }^{1} \mathrm{H}$-NMR spectra of $\mathrm{AB}-1 \mathrm{c}$ in $\left(\mathrm{CD}_{3}\right)_{2} \mathrm{CO}$ before (a) and after (b) adding $\mathrm{CH}_{3} \mathrm{SO}_{3} \mathrm{H}$

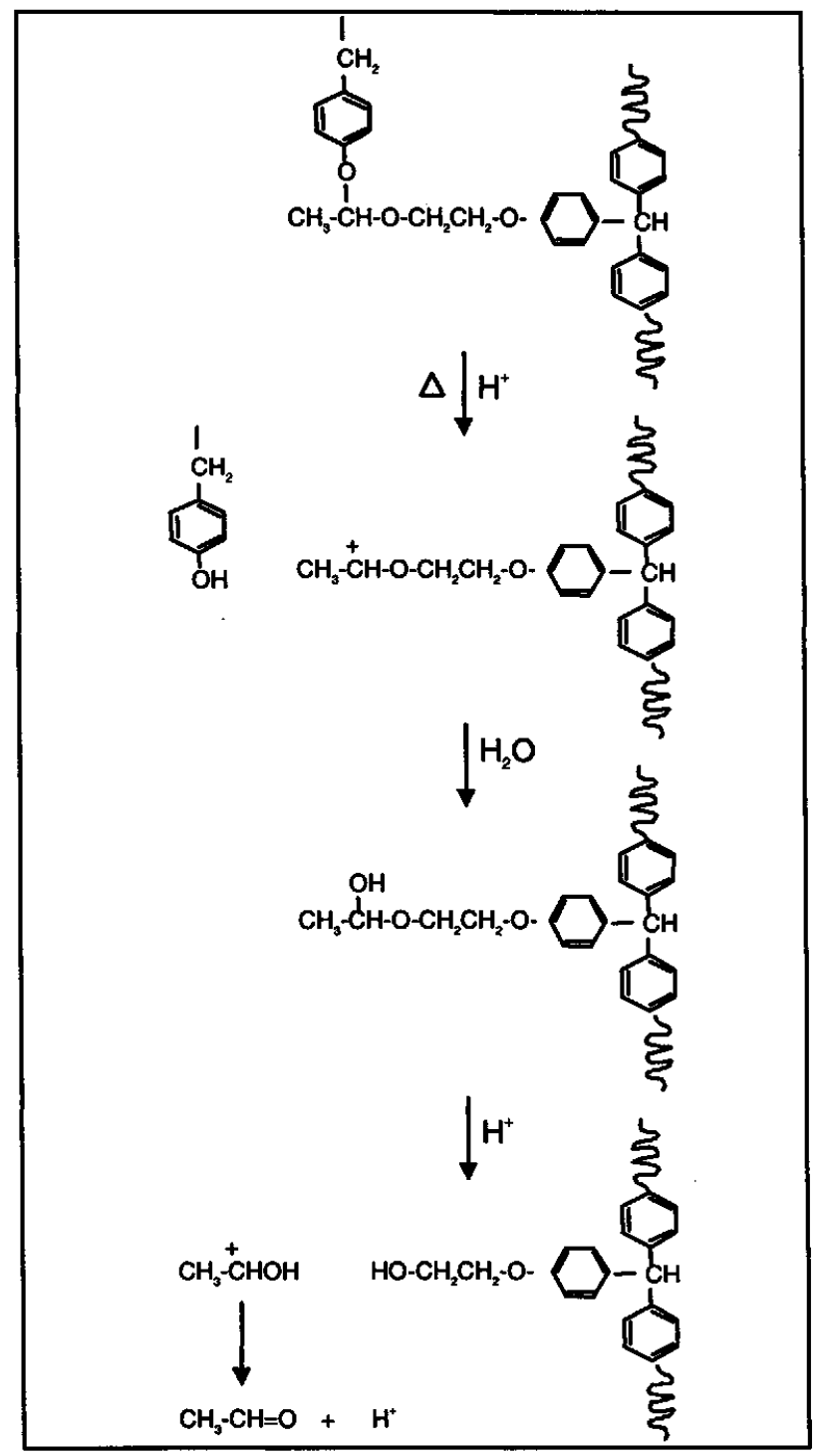

Figure 7 An acid-catalyzed fragmentation of $\mathrm{AB}$ resin.

the resist were unchanged. Also, when the PEB temperature was varied in the range of $80-100^{\circ} \mathrm{C}$, the sensitivity reached a plateau at or above $90^{\circ} \mathrm{C}$.

The effects that the kind of $\mathrm{AB}$ resin have on the exposure characteristics are shown in Figure 11. The resist compositions were $A B$ resin/EtSB=100/4 (wt. ratio). The evaluated $A B$ resins were $A B-1 c, A B-2 c$, and $A B-3 c$. Although these resins showed no significant contrast reduction, there was a large difference in their sensitivity. In particular, the sensitivity for $A B-3 c$ was about one order of magnitude higher than that for AB-1c. Since these resins (AB-1c and AB-3c) contain almost the same content of the acetal groups, we ascribe the difference in sensitivity to the molecular size of the vinylether backbone structure and/or the dissolution promotion of a cleavage product. 


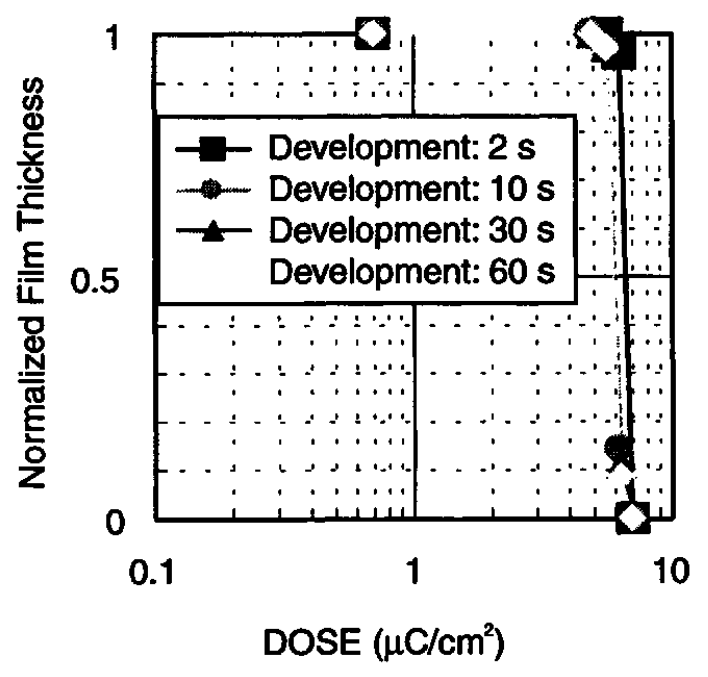

Figure 8 Effect of development time on the exposure characteristics of a resist with $\mathrm{AB}-1 \mathrm{c}$. Resist composition: $\mathrm{AB}-1 \mathrm{c} / \mathrm{EtSB}=100 / 4$ (wt. ratio) PB: $100^{\circ} \mathrm{C}$ for $5 \mathrm{~min}$. PEB: $100^{\circ} \mathrm{C}$ for $2 \mathrm{~min}$. Film thickness: $350 \mathrm{~nm}$

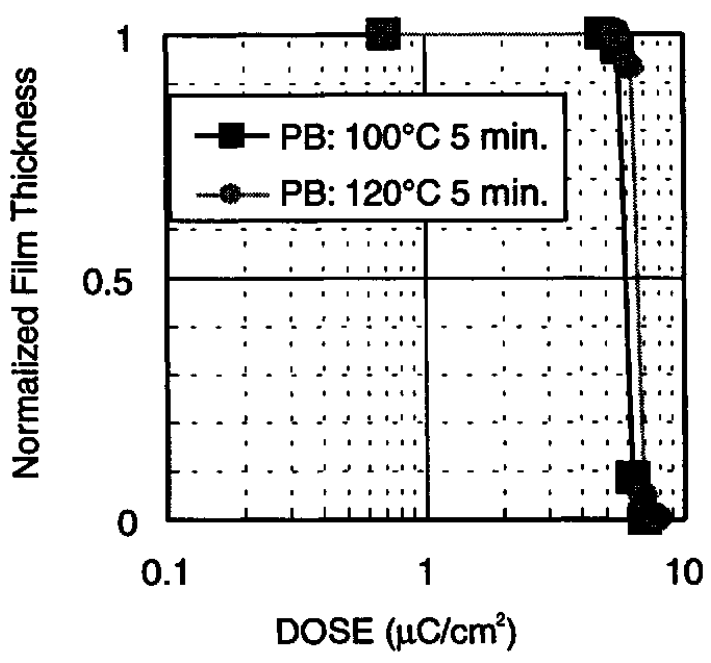

Figure 9 Effect of PB temperature on the exposure characteristics of a resist with $\mathrm{AB}-1 \mathrm{c}$. Resist composition: $\mathrm{AB}-1 \mathrm{c} / \mathrm{EtSB}=100 / 4$ (wt. ratio) PEB: $100^{\circ} \mathrm{C}$ for $2 \mathrm{~min}$.

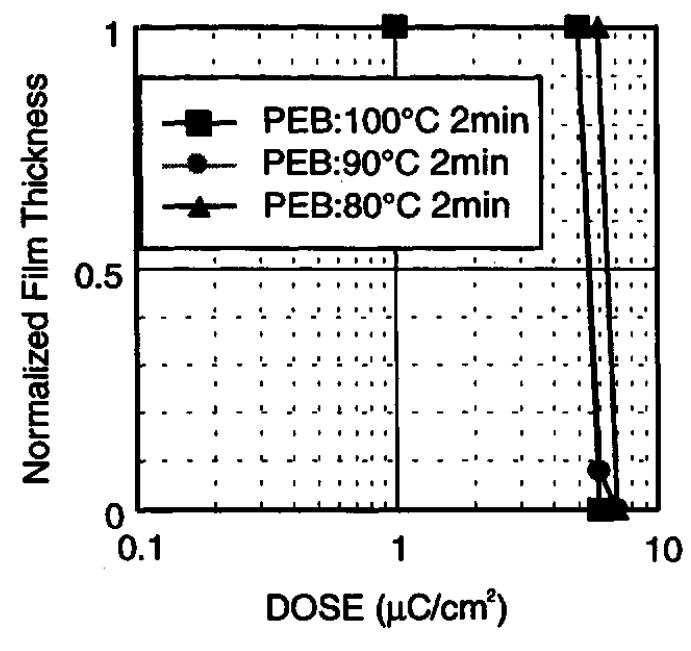

Figure 10 Effect of PEB temperature on the exposure characteristics of a resist with $\mathrm{AB}-1 \mathrm{c}$. Resist composition: $\mathrm{AB}-1 \mathrm{c} / \mathrm{EtSB}=100 / 4$ (wt. ratio) $\mathrm{PB}: 100^{\circ} \mathrm{C}$ for $2 \mathrm{~min}$.

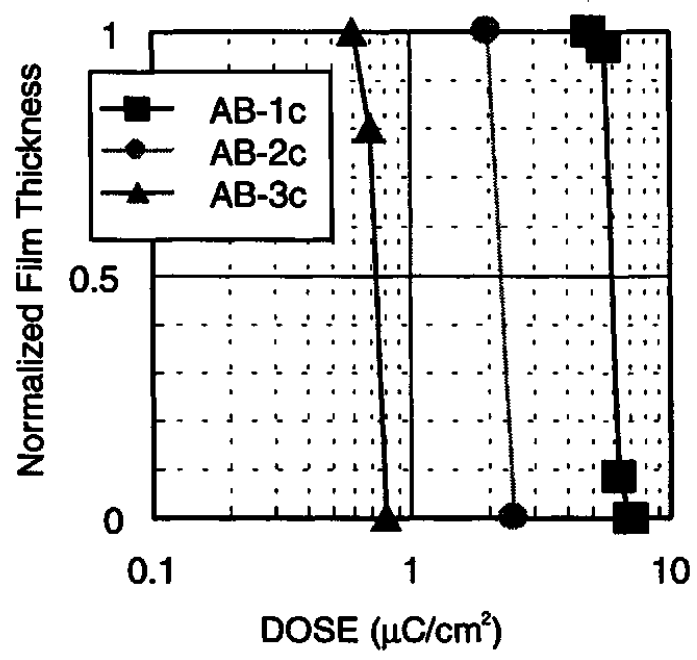

Figure 11 Exposure characteristics of resists with $\mathrm{AB}$ resins. Resist composition: $\mathrm{AB}$ resin $/ \mathrm{EtSB}=100 / 4$ (wt. ratio) PB: $100^{\circ} \mathrm{C}$ for $5 \mathrm{~min}$. PEB: $100^{\circ} \mathrm{C}$ for $2 \mathrm{~min}$. Development time: $60 \mathrm{~s}$. 
Preliminary patterning of the resist using $A B-1 c$ and $A B-3 c$ was carried out with a $30 \mathrm{kV}$ EB writer. The resist compositions were $\mathrm{AB}$ resin/NAINO=100/4 (wt ratio). The observed patterns showed a T-top profile due to the formation of an insoluble surface layer. Therefore, patterning of the resist using $A B-2 b$ was carried out. As the dissolution rate of $A B-2 b$ was too high to use the $2.38 \%$ TMAH developer, dilute TMAH (1.19\%) was used as a developer. Scanning electron micrographs of a typical delineated pattern are shown in Figure 12. Even though the optimization of the resist composition and process conditions was still insufficient, we were able to open 110-nm line-and-space (L/S) patterns at a dose of $4.0 \mu \mathrm{C} / \mathrm{cm}^{2}$ for an initial $0.22-\mu \mathrm{m}$ film thickness, and $80-\mathrm{nm}$ L/S patterns were resolved with a dose of $5.0 \mu \mathrm{C} / \mathrm{cm}^{2}$. However, each pattern tended to have a T-top profile and considerable line edge roughness. We are now investigating the cause of these phenomena.

\section{Conclusion}

We have developed a novel acid-breakable (AB) resin obtained through the condensation of polyphenol with multi-functional vinylether compounds. Synthesized resins made with a $50 \%$ vinylether feed ratio gave a high $\mathrm{MW}(\mathrm{Mw}>5000)$ and were insoluble in an aqueous alkali developer (2.38\% TMAH). The photogenerated acid induced fragmentation of the resin to produce low MW components. Among these resins, the resin with bisvinylether (EVE-3) showed the highest sensitivity $\left(0.8 \mu \mathrm{C} / \mathrm{cm}^{2}\right)$. The resist with $\mathrm{AB}-2 \mathrm{~b}$ for a $30 \mathrm{kV}$ EB writer could resolve $80-\mathrm{nm} \mathrm{L} / \mathrm{S}$ patterns with a dose of $5.0 \mu \mathrm{C} / \mathrm{cm}^{2}$.

\section{Acknowledgments}

We express to our gratitude to Dr. Sumio Hosaka for use of the EB writer, and to Takashi Hattori for his useful advice on NMR measurement.

\section{References}

1) H. Shiraishi, N. Hayashi, T. Ueno, T. Sakamizu, and F. Murai, J. Vac. Sci. \& Technol. B9 (1991) 3343.

2) T. Sakamizu, T. Arai, K. Katoh, S. Uchino, F. Murai, Y. Suzuki, and H. Shiraishi, $J$. (a)

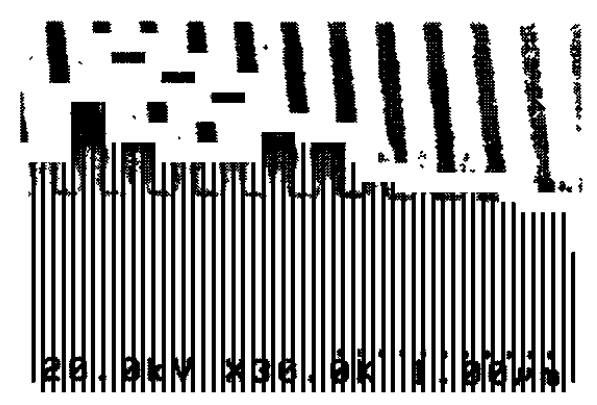

(b)

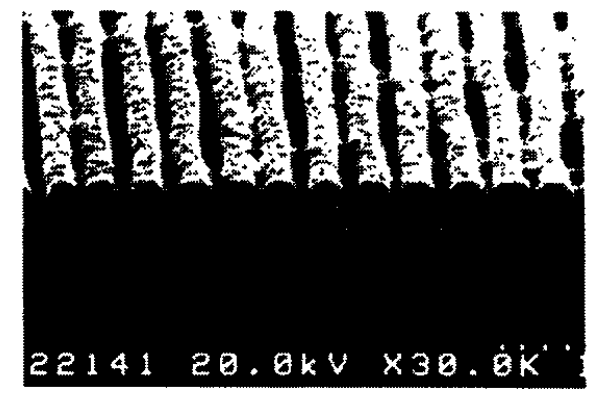

(c)

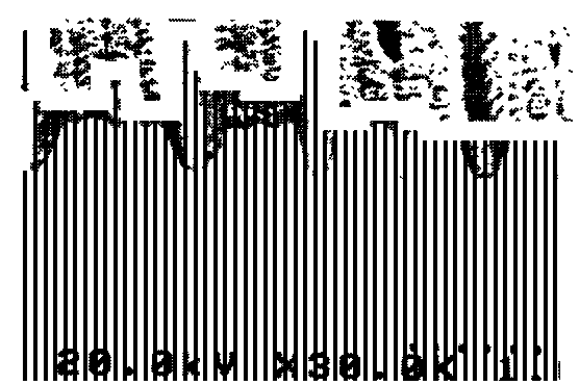

Figure 12 Scanning micrographs of (a) $110 \mathrm{~nm} \mathrm{L \& S}$, (b) $100 \mathrm{~nm}$ L\&S, (c) $80 \mathrm{~nm}$ L\&S patterns obtained by electron-beam exposure at $30 \mathrm{kV}$. Process conditions: $\mathrm{PB} 90^{\circ} \mathrm{C}$ for $2 \mathrm{~min}, \mathrm{PEB} 90^{\circ} \mathrm{C}$ for $2 \mathrm{~min}$, development time of $60 \mathrm{~s}$, and exposure dose of (a), (b) $4.0 \mu \mathrm{C} / \mathrm{cm}^{2}$, and (c) $5.0 \mu \mathrm{C} / \mathrm{cm}^{2}$

Photopolymer Sci. Technol., 11 (1998) 547.

3) H. Shiraishi, T. Yoshimura, T. Sakamizu, T. Ueno, and S. Okazaki, J. Vac. Sci. \&Technol., B12, (1994) 3895.

4) H. Ito and C. G. Willson, Polym. Eng. Sci., 23 
(1983) 1012.

5) J. M. J. Fréchet, F. Bouchard, F. Houlihan, B. Kryczka, and C. G. Willson, ACS Polym. Mater. Sci. Eng., 53 (1985) 263.

6) H.-T. Schacht, N. Muenzel, P. Falcigno, H. Holzwarth, and J. Schneider., J. Photopolymer Sci. Technol., 9 (1996) 573.

7) J. V. Crivello and D. A. Conlon, J. Polym. Sci., Polym. Chem. Ed, 21 (1983) 1785.

8) S. Moon, K. Naitoh, and T. Yamaoka, Chem. Mater. 5 (1993) 1315.

9) H. Ito, G. Breyta, and D. Hofer, Proc. SPIE, 53 (1995) 2438.
10) T. Ueno, H. Shiraishi, L. Schlegel, N. Hayashi, and T. Iwayanagi, Polymers for MicroelectronicsScience and Technology, Kodansha, Tokyo, 413 (1990).

11) T. Arai, T. Sakamizu, K. Katoh, M. Hashimoto, and H. Shiraishi, J. Photopolymer Sci. Technol., 10 (1997) 625.

12) C. Mertesdorf, N. Münzel, P. Falcigno, H. J. Kimer, B. Nathal, H. T. Schacht, R. Schulz, S. G. Slater, and A. Zettler, Acs Symp., 614 (1995) 35. 13) S. Moon, K. Kamenosono, S. Kondo, A. Umehara, and T. Yamaoka, Chem. Mater. 6 (1994) 1854. 